\title{
Comparison of haemodynamic alteration with laryngeal mask airway and endotracheal tube in intermediate duration of gynaecological operation
}

\author{
Azizul Gafur1*, Mustafa Kamal ${ }^{1}$, Ashia Ali², Idris Ali ${ }^{3}$, Amirul Islam ${ }^{4}$, Abdul Kuddus Khan ${ }^{5}$
}

${ }^{* 1}$ Department of Anaesthesiology \& ICU, Zahurul Islam Medical College \& Hospital, Bajitpur, Kishorgong, ${ }^{2}$ Cardiac Anaesthesia Unit, Department of Anaesthesia, Analgesia \& Intensive Care Medicine, BSMMU, Shahbag, Dhaka, ${ }^{3}$ Dhaka Dental College, Dhaka, ${ }^{4}$ Department of Anaesthesia, Analgesia \& Intensive Care Medicine, BSMMU, Shahbag, Dhaka, ${ }^{4}$ Department of Anaesthesiology, NICVD, Dhaka, ${ }^{1}$ Department of Anaesthesia, Analgesia \& Intensive Care Medicine, BSMMU, Shahbag, Dhaka.

*Corresponding author: <azizul gafur@yahoo.com>

\begin{abstract}
Background Laryngeal mask airway insertion causes less changes of haemodynamic parameters. As haemodynamic changes during laryngoscopy and endotracheal intubation as result of intense stimulation of sympathetic nerves system.

Objective To find out the effective airway management by LMA during controlled ventilation, to avoid laryngoscopic and intubation induced haemodynamic changes and to avoid laryngospasm and bronchospasm.

Method A total number of 100 patients ASA grade I \& II were selected randomly as per inclusion and exclusion criteria in two groups. Fifty in each group. In group A used LMA and in group B used ETT during general anaesthesia in intermediate duration of gynaecological operation. Pulse,NIBP,SpO2 were recorded in perioperatively.
\end{abstract}

Result Pulse, blood pressure were significant between the two groups $(p<0.00)$ but in SpO2 was insignificant except in 2 min of intraoperative which was significant. $(p<0.013)$.

Conclusion LMA insertion causes less changes of haemodynamic parameters when compared with that of ET intubation. Our finding suggests that LMA can be safe and beneficial alternative to ETT.

Keywords Laryngeal mask airway, endotracheal tube, gynaecological, haemodynamic.

(JBSA 2010; 23(2): 51-55)

\section{Introduction}

The Laryngeal Mask Airway ${ }^{1,2}$ has been designed as the missing link between the face mask and the tracheal tube ${ }^{3}$ and it has been gained wide spread popularity. Advantages includes ease of use, efficient airway management, airtight seal if properly inserted ${ }^{4}$, it frees the anaesthetist's hands. In most patients it can be inserted without laryngoscopy. Device is well tolerated by patient during recovery from anaesthesia. As haemodynamic changes during laryngoscopy and endotracheal intubation as a result of intense stimulation of sympathetic nervous system. These changes can be dangerous in patients with cardiovascular and cerebrovascular diseases as they may lead to intra operative and post operative life threatening consequences like ischaemia, infarction or cerebral hemorrhage. To avoid these complication LMA can be used as an alternative to endotracheal intubation for airway management during anaesthesia for intermediate duration of procedure-like total abdominal hysterectomy, vaginal hysterectomy, open ovarian cystectomy and laparoscopic ovarian cystectomy. There is an attenuated haemodynamic response to insertion of LMA as compared to endotracheal intubation ${ }^{5,6}$. In another study it was found that there is some haemodynamic alteration to insertion of LMA as compared to endotracheal intubation ${ }^{7}$. 
LMA insertion can be done without laryngoscopic assistance. LMA can be useful during management of difficult and failed intubation. It is also useful in patients with distorted airway anatomy as in tumour in the face and neck, congenital problems, poor cervical spine mobility. Sore throat can be avoided by using LMA which is some times a complication of endotracheal intubation. Insertion of LMA is possible with the patients neck and head in any position and with practice the operator can insert it from the side or from infront of the patient ${ }^{8}$.LMA is reusable and can be reused up to 40 times and cost effective when used in place of disposable single use of tracheal tube.

To establish the benefits of LMA, more specifically the haemodynamic stability with LMA, we compare the cardiovascular response to LMA insertion and endotracheal intubation in intermediate duration (1-2 hours) operations with IPPV maintained manually. The LMA is in popular use for gynaecological surgeries (such as laparoscopy $)^{9}$.

\section{Methods}

After taking informed consent, all patients were premedicated with oral Ranitidine $150 \mathrm{mg}$. the night before and the morning of surgery. After bringing the patient to the operation theater standard monitoring, comprising non-invasive blood pressure and pulse oximetry was attached to the patient and base-line blood pressure and heart rate was recorded. Pre oxygenation was done appropriately prior to induction of all hundred patients $(50$ patients in each group).Patient with H/O gastro esophageal reflux, hiatal hernia, previous esophageal and gastric surgery, were excluded from this study.Patient among the sample was assigned in two groups randomly by blind envelop method. 100 envelops of which 50 for group-A and 50 for group-B were kept in a box.

All patients were preoxygenated with well fitted face mask with oxygen at a rate of $>6 \mathrm{~L} /$ minute for 3-5 minutes. Induction of general anaesthesia was performed with injection thiopenton sodium $5 \mathrm{mg} / \mathrm{kg}$ IV, Inj. fentanyl $1 \mu \mathrm{gm} / \mathrm{kg}$ IV, Inj. suxamethonium bromide $2 \mathrm{mg} / \mathrm{kg}$ IV. After that LMA of size 3 and 4 were inserted according to the patient status and then cuff of the LMA was inflated with $20 \mathrm{ml}$ and $30 \mathrm{ml}$ (respectively) of air, then anaesthesia was maintained with $\mathrm{O}_{2} / \mathrm{N}_{2} \mathrm{O}$ and halothane $0.5 \%$. Muscle relaxation was ensured by Inj. Vecuronium bromide $0.1 \mathrm{mg} / \mathrm{kg}$. bolus IV followed by $25 \%$ of the initial bolus dose of vecuronium bromide every 20 minutes interval. Additional doses of Inj. fentanyl 0.5 to $1 \mu \mathrm{gm} / \mathrm{kg} /$ hr were administered, through out the duration of surgery.Following the completion of surgery, muscle relaxation was antagonized with Inj. neostigmine $0.05 \mathrm{mg} / \mathrm{kg}$ and Inj. atropine $0.02 \mathrm{mg} /$ $\mathrm{kg}$ IV together. Before removal of LMA all patients were allowed to breath spontaneously and wake up with the device in place. Immediately after removal of LMA and endotracheal tube patients haemodynamic parameters were recorded. Study parameters in pre-operative period Pulse, NIBP, SpO2.and Intra operative Pulse, NIBP, $\mathrm{SpO}_{2}$, vomiting, laryngospasm, gastric insuflation, aspiration, cough and Post operative Pulse, NIBP, $\mathrm{SpO}_{2}$, vomiting, regurgitations.

\section{Results}

Observation of the present study was analyzed in the light of comparison among the subject groups, each group having $n=50$. All result are expressed as mean \pm standard deviation (SD). The studied groups became statistically matched for age $(p=0.624)$, weight $(p=0.422)$.

Table I Demographic data of study groups

\begin{tabular}{lccc}
\hline Parameter & $\begin{array}{c}\text { Group A } \\
\text { (LMA) }\end{array}$ & $\begin{array}{c}\text { Group B } \\
\text { (ETT) }\end{array}$ & $\begin{array}{c}\text { P } \\
\text { value }\end{array}$ \\
\hline Age & $25.932 \pm 10.17$ & $26.872 \pm 8.91$ & 0.624 \\
Weight & $47.81 \pm 6.98$ & $48.99 \pm 7.63$ & 0.422 \\
\hline
\end{tabular}

Values are expressed as mean \pm SD. Data are analyzed by student's ' $t$ ' test.

There was no significant changes,

NS - Not significant 
Table II Changes of pulse rate between two study groups

\begin{tabular}{lccccc}
\hline Group/ Time & Base line & 2 Min. & 5 Min & 10 min & Removal \\
\hline Group-A (LMA) & $78.54 \pm 8.67$ & $79.92 \pm 7.61$ & $78.96 \pm 6.23$ & $74.36 \pm 6.61$ & $69.48 \pm 6.77$ \\
Group-B (ETT) & $71.20 \pm 5.00$ & $104.00 \pm 6.84$ & $108.58 \pm 5.02$ & $91.64 \pm 9.54$ & $109.52 \pm 6.73$ \\
P value & 0.000 & 0.000 & 0.000 & 0.000 & 0.000 \\
\hline
\end{tabular}

Values are expressed as mean \pm SD. Data are analyzed by student's ' $t$ ' test.

There was significant difference in pulse rate between groups from base line to removal of the tube i.e., $(\mathrm{p}=0.000)$.

Table III Changes of systolic blood pressure

\begin{tabular}{lccccc}
\hline Group/ Time & Base line & 2 Min. & 5 Min & 10 min & Removal \\
\hline Group-A (LMA) & $103.10 \pm 6.22$ & $105.10 \pm 5.60$ & $101.86 \pm 4.79$ & $104.46 \pm 5.34$ & $105.08 \pm 5.75$ \\
Group-B (ETT) & $101.58 \pm 7.132$ & $130.92 \pm 13.00$ & $130.92 \pm 9.83$ & $126.40 \pm 13.92$ & $138.50 \pm 8.41$ \\
P value & 0.259 & 0.000 & 0.000 & 0.000 & 0.000 \\
\hline
\end{tabular}

Values are expressed as mean \pm SD. Data are analysed by student's 't' test.

There was significant changes in systolic blood pressure between groups except base line systolic blood pressure which was insignificant. ie $(\mathrm{p}=0.259)$.

Table IV Changes of diastolic blood pressure between study groups

\begin{tabular}{lccccc}
\hline Group/ Time & Base line & 2 Min. & 5 Min & 10 min & Removal \\
\hline Group-A (LMA) & $65.94 \pm 3.75$ & $65.62 \pm 4.19$ & $69.52 \pm 4.51$ & $65.86 \pm 3.53$ & $66.86 \pm 3.37$ \\
Group-B (ETT) & $67.20 \pm 4.33$ & $88.40 \pm 4.90 .00$ & $90.34 \pm 3.48$ & $84.26 \pm 6.60$ & $92.06 \pm 4.28$ \\
P value & 0.123 & 0.000 & 0.000 & 0.000 & 0.000 \\
\hline
\end{tabular}

Values are expressed as mean \pm SD. Data are analyzed by student's ' $t$ ' test

There was significant changes in diastolic blood pressure between groups except base line diastolic blood pressure. ie $(\mathrm{p}=0.123)$.

Table V Changes in $\mathrm{SpO}_{2}$

\begin{tabular}{lccccc}
\hline Group/ Time & Base line & 2 Min. & 5 Min & 10 min & Removal \\
\hline Group-A (LMA) & $98.58 \pm .70$ & $98.64 \pm .70$ & $99.30 \pm .76$ & $99.34 \pm .77$ & $99.52 \pm .71$ \\
Group-B (ETT) & $98.86 \pm .83$ & $99.04 \pm .88$ & $99.50 \pm .73$ & $99.56 \pm .73$ & $99.66 \pm .69$ \\
P value & .072 & .013 & .185 & .147 & .318 \\
\hline
\end{tabular}

Values are expressed as mean \pm SD. Data are analyzed by student's ' $t$ ' test.

There was no significant difference between groups.

\section{Discussion}

Haemodynamic stability is an important goal of any anaesthetic management plan but haemodynamic alterations during endotracheal intubation especially in patients with heart disease, hypertension, increase ICP etc. are a big problem for anaesthesiologist. So it is highly desirable for anaesthesiologist to reduce these haemodynamic alteration by using newer techniques or drugs. A study by Verghese C et al. (1993) has done a prospective survey of the use of the laryngeal mask airway in 2359 patients undergoing anaesthesia 
in which the laryngeal mask airway was used were prospectively audited over a 6 -month period. A simple record sheet was completed at the time of anaesthetic administration and 2359 completed forms were analysed to assess problems encountered with its use. It was used successfully in 2350 patients (99.61\%); of these, 1399 patients (59\%) breathed spontaneously through the airway and 960 patients (41\%) underwent intermittent positive pressure ventilation of the lungs. Two patients $(0.08 \%)$ were reported to have regurgitated during the use of the laryngeal mask airway, but no serious sequelae associated with its use were encountered ${ }^{13}$.Holden $\mathrm{R}$ et al. (1991) intra-ocular pressure was measured before and throughout airway establishment with either the laryngeal mask airway and tracheal tube. Similar measurements were made on removal of either airway and the amount of coughing noted in the first minute after removal. There was a significantly smaller increase in intra-ocular pressure $(p<0.001)$ using the laryngeal mask airway both on placement and removal, than with the tracheal tube. Postoperative coughing was significantly reduced using the laryngeal mask airway $(p<0.001)$. There was a significantly greater rise in heart rate using the tracheal tube $(p<0.01)$ probably related to an increased cardiovascular response. The laryngeal mask airway is recommended as an alternative to tracheal intubation in routine and emergency intra-ocular surgery ${ }^{10}$.

Some medication can be used to modify haemodynamic responses to laryngoscopic endotracheal intubation and these includes the use of premedication like, lignocane ${ }^{7}$, fentanyl, esmolol and magnesium. But none of these pharmacological intervention was found effectively reducing the haemodynamic responses rather they are causing complications as there side effects.

Kihara et al. had demonstrated that LMA insertion has no significant haemodynamic effect compared to base line. They also shown that LMA removal too did not change haemodynamic parameter significantly ${ }^{8}$. In our study, LMA insertion compared to ETT intubation demonstrates statistically significant haemodynamic effect in ETT group.

Idress \& Khan et al. in another study demonstrated LMA insertion and ETT intubation (for IPPV) that
LMA did significantly attenuate $(\mathrm{P}<0.05)$ haemodynamic response compared to ETT group which is as like as our study. They also showed the cardiovascular response to extubation was similar in both LMA \& ETT group ${ }^{4}$.

Kihara et al. has demonstrated that LMA had no significant change on heart rate, systolic blood pressure, diastolic blood pressure compared to Macintosch laryngoscopy in hypertensive patient ${ }^{11}$. An our study we used normotensive sample and found the same result. However, for reason less understood. Kihara et al. did not found significant high pressure response in ETT group in normotensive patient. One reason may be they used propofol as induction agent which has better haemodynamic attenuation than thiopentone induction ${ }^{12}$. The later was used in our sample. Propofol $2 \mathrm{mg} / \mathrm{kg}$ induction was used in Yamallchl et al. series where they used LMA in normotensive and hypertensive group and compared to both groups and found similar haemodynamic response and concluded that propofol is an effective induction method preventing adverse cardiac response to LMA. But they did not compare with ETT.

Braude $\mathrm{N}$ et al. compared the haemodynamic response of LMA insertion with insertion of oropharyngeal airway. They showed that small rise in heart rate, blood pressure and intraocular pressure of LMA insertion compared with that of oropharyngeal airway. In our study less rise of heart rate, systolic blood pressure, diastolic blood pressure in LMA insertion compared with that of ET intubation.

Holders $\mathrm{R}$ et al showed an attenuated pressure response associated with laryngeal mask airway insertion compared with conventional laryngoscopy and tracheal intubation. In our Study we observed similar results.

In our study we used LMA and endotracheal tube in ASA Grade-I and Grade-II patients and we found less haemodynamic change with laryngeal mask insertion during the maintenance of anaesthesia in intermediate duration operation (1-2 hours) like, total abdominal hysterectomy, vaginal hysterectomy, open ovarian cystectomy and laparoscopic ovarian cystectomy in controlled ventilation done manually and there was no problem in maintaining $\mathrm{SpO}_{2}$ in accurately placed laryngeal mask airway instead of endotracheal 
tube.In my study groups no cases were found to develop significant regurgitation and aspiration in the perioperative period and all patients with LMA were maintained $\mathrm{SpO}_{2}$ above $98 \%$ during the peroperative maintenance of airway.

Although in many occasions of short durated operations LMA were used safely without the complications of regurgitation and aspiration and haemodynamic alteration induced hazards. We also found its safe use in intermediate duration operation without any regurgitation and aspiration and CVS and cerebrovascular complications due to haemodynamic changes. Conclude that LMA insertion causes less changes of haemodynamic parameters when compared with that of ET intubation. Our finding suggests that LMA can be safe and beneficial alternative to ETT for ASA Grade-I and II patients undergoing intermediate duration of elective gynaecological operation in controlled ventilation done manually

\section{References}

1. Laryngeal mask airway. Lancet 1991; 338: 1046-7

2. Brain AIJ. The laryngeal mask a new concept in airway management. $\mathrm{Br} \mathrm{J}$ Anaesth 1983; 55: 801-5

3. Brodrick PM.Webster NR, Nunn JF. The laryngeal mask airway. A study of 100 patients during spontaneous breathing. Anaesthesia 1989; 44: 238-41
4. Cyna AM, Macleod DM, Campbell JR, Criswell J, JOH R, The laryngeal. mask: cautionary tales, Anaesthesia 1990; 45: 167-8

5. Idrees A, Khan FA. A comparative study of positive pressure ventilation via LMA and endotracheal tube. J Pak Med Assoc 2000; 50: 333-8

6. Braude N. elements EAF. Hodges UM. Anaesthesia 1989;44:551-4

7. Wison IG, Fell D, Robinson SL, Smith G. Cardiovascular response to insertion of the laryngeal mask. Anesthesia 1992;47:300-2

8. Hickey S, Cameron AE, A Ashury AJ. Cardiovascular response to insertion of Brain's laryngeal mask. Anaesthesia 1990;45:629-33

9. Holden R, Morsman CDG, Butler J, Clark GS, Hughes DS and Bacon PJ. Intra-ocular pressure changes using the laryngeal mask airway and tracheal tube. Anaesthesia. 1991;46:922-24

10. Rilay RH, Swan HD. Value of the laryngeal mask airway during thoracotomy. Anaesthesiology 1992;77:1051

11. Stone DJ, GalTJ.Airwaymanagement.In. MillerRD,editor.Anaesthesia. $3^{\text {rd }}$ ed. New York,Churchill Livingstone 1990;2:1265-71

12. Verghese $\mathrm{C}$ et al. Prospective surgery of the use of the laryngeal mask airway in 2359 patients. Anaesthesia 1993;48:58-60 